\title{
Performances e memória em expressões televisivas ${ }^{1}$
}

\section{Performance and memory in televisional expressions}

\section{Jorge Cunha Cardoso Filho}

Doutor em Comunicação pela Universidade Federal de Minas Gerais (UFMG), professor do Programa de Pós-Graduação em Comunicação e Cultura Contemporâneas, UFBA, e do Centro de Artes, Humanidades e Letras da UFRB.

<cardosofilho.jorge@gmail.com>

\section{Juliana Freire Gutmann}

Doutora em Comunicação e Cultura Contemporâneas pela Universidade Federal da Bahia (UFBA). Docente do Departamento de Comunicação e coordenadora do POSCOM, UFBA.

<jugutmann@gmail.com>

Rafael José Azevedo

Doutorando em Comunicação pela Universidade Federal de Minas Gerais (UFMG). $<$ rafaeljoseazevedo@gmail.com>

\section{RESUMO}

Este artigo se propõe a compreender como operam os aspectos constitutivos das performances e da memória em produções televisivas que estão constituídas na interface com a música popular. A partir dos chamados performance studies, e com ênfase analítica na relação texto-contexto, discutimos neste estudo como se entrelaçam questões referentes ao discurso informativo e à fabulação como um padrão atual de construção narrativa a partir da análise de trechos do programa Ensaio, veiculado pela TV Cultura, desde os anos 1990, e do Jornal da MTV, exibido entre 2002 e 2007 pela extinta MTV Brasil. Esses padrões, de acordo com as inferências conclusivas, contribuem para a produção de uma estabilidade contextual provisória dos produtos e, nesse sentido, também contribuem para a construção e para a perpetuação da memória.

Palavras-chave: Memória. Televisão. Música popular.

\section{ABSTRACT}

This article proposes to understand how constitutive aspects of performances and memory operate in television productions that are built in the interface with popular music. From the performance studies and with analytical emphasis on the text-context relationship, we discuss how issues related to information discourse and fable making as a current pattern of narrative construction based on the analysis of excerpts from the Ensaio program, broadcast by TV Cultura since the 1990s and the Jornal da MTV, which was screened between 2002 and 2007 by the extinct MTV Brasil. These patterns contribute to the production of a provisional contextual stability of the products and, in this sense, also contribute to the construction and perpetuation of memory.

Keywords: Memory. Television. Popular music.

\section{Introdução}

Quando nos deparamos com os produtos audiovisuais que atualmente abundam o universo da Comunicação temos a impressão que o referente ao qual tais produtos se vinculam não podem ser simplesmente pensados pela lógica do "mundo ficcional x mundo real". Isso porque tais produtos parecem ter

1 Pesquisa financiada pelo CNPq. 
reverberações para além do campo estritamente audiovisual e mesmo porque algumas de suas narrativas jogam com as marcas do documental e do ficcional, borrando os limites clássicos dessas convenções.

No campo televisivo, mesmo os produtos considerados tradicionalmente como casos emblemáticos dessas distintas formas narrativas apresentam momentos de articulação entre o documento e a fabulação, como os formatos telejornalísticos (que usam simulações e arte constantemente para "demonstrar" seus pontos de vista). Em termos de potência estético-política, essa relação nos instiga a questionar quais as incidências que tal operação institui nos regimes de seleção e organização das narrativas, visando a estabilização da memória coletiva em contextos.

Em nossa perspectiva, os contextos são estruturas consolidadas da memória coletiva que servem como enquadramentos para determinados temas, fenômenos e acontecimentos. Nesse sentido, o par dicotômico ficcional $x$ documental serve como um desse enquadramentos, tensionado em diversos momentos no campo da produção audiovisual, promovendo rasuras. Para tanto, nos debruçamos sobre dois produtos do universo televisivo brasileiro que estão afastados temporalmente (numa perspectiva de análise anacrônica): o programa Ensaio, veiculado pela TV Cultura desde os anos 1990 e o Jornal da MTV, exibido entre 2002 e 2007 pela extinta MTV Brasil.

Formulamos nosso problema de investigação a partir dos Performance Studies, especificamente da noção de performance, que se revela enquanto forma-força que se altera no momento mesmo da ação (não sendo a mera representação de uma ação). As performances devem ser entendidas enquanto comportamentos restaurados (Schechner, 2006), tanto reflexiva quanto simbolicamente. Ao mesmo tempo em que se tem acesso a uma tradição, a performance chama atenção para o que está acontecendo naquela situação podendo, inclusive, instituir rupturas nessas tradições às quais pertencem.

\footnotetext{
A imagem faz conviver com sua dimensão representacional, uma dimensão performativa: ali, se performam formas de vida. Seja na mídia, nas artes visuais ou no cinema, não são poucas as experiências em que as imagens parecem não apenas representar ou figurar - não apenas, ressaltemos logo - mas inventar, produzir formas de vida, estas que mantêm com a obra uma relação de continuidade (em certos aspectos) e descontinuidade (em outros). Isso nos permitiria afirmar que as performances que ali se produzem (dos autores e dos personagens) estão, simultaneamente, no mundo vivido e no mundo imaginado, elas são, a um só tempo, forma de vida e forma da imagem (Brasil, 2014, p. 133).
} 
As performances dos personagens dos programas televisivos aqui analisados, em nossa formulação, instituem efeitos ora ficcionais ora documentais e nos mostram, simultaneamente, tanto as matrizes convencionais dessas ações quanto seus aspectos disruptivos em determinados acontecimentos. Daí nos interessarmos pelos aspectos gestuais, olhares, corporalidade, enunciação desses personagens numa situação de comunicação específica e também planos, iluminação, movimentos de câmera e sonorização que implicam o dispositivo audiovisual. Nos apropriamos de figuras conceituais enquanto operadores analíticos que nos permitissem o mapeamento da convenção, mas também dos borramentos e desestabilizações com o convencionalizado.

Essas operações da performance, então, contribuem para a construção da memória em sua dimensão seletiva e vinculada aos dissensos cotidianos. Mesmo a memória individual possui essa condição limiar. Se pensamos que memória é perpetuada por uma série de dispositivos - desde a narrativa mítica grega há essa demonstração - percebemos que ela não se dirige apenas ao passado, mas também ao horizonte de possibilidades aberto por sua enunciação. No nosso caso, construído pelo campo midiático televisivo e musical.

Dispositivos televisivos, sejam eles do âmbito do entretenimento ou do campo da informação, tem jogado com um forte efeito de coabitação do documental com o ficcional. Fazem isso, a partir de uma mescla entre formas de vida e formas da imagem (Brasil, 2014), entre aspectos biográficos dos personagens e aspectos encenados e modulados, amparados pelas próprias linguagens audiovisuais.

Concluímos, desse modo, que não há uma indistinção entre essas figurações (documental e ficcional), mas uma potencialidade de trânsito que indica como as expressões audiovisuais ensinam sobre os valores que vigoram no âmbito dos comportamentos restaurados e da organização narrativa da memória.

\section{Redes de Contextualização}

Destacar os enlaces entre os campos da Comunicação e da História vem sendo um dos principais objetivos da rede de pesquisa que construímos nos últimos três anos ${ }^{2}$. De modos muito diversos e com perspectivas teóricas

2 A primeira reunião do projeto Historicidade dos Processos Comunicacionais ocorreu no âmbito do Programa de Pós-Graduação em Comunicação da UFMG, em 2015, como resultado da iniciativa de um acordo de cooperação construído com programas de pós-graduação parceiros. A partir de então outras três atividades se desenvolveram na UFBA, UFRJ e UFPI, entre os anos de 2015 e 2016. 
heterodoxas, a rede constituída por pesquisadores de instituições como Universidade Federal de Minas Gerais, Universidade Federal de Ouro Preto, Universidade Federal do Rio de Janeiro, Universidade Federal da Bahia, Universidade Federal do Recôncavo da Bahia e Universidade Federal do Piauí, tem buscado identificar como algumas figurações de historicidade são constituídas pela própria relação com a sociedade mediatizada e reforçadas por gramáticas discursivas, cujo objetivo é levar essas figurações a um campo de estabilidade e naturalização. Assim, constrói-se quadros contextuais que "ajudam" a compreender determinados processos comunicacionais e históricos. Mas essa "ajuda" deve ser sempre colocada, assim mesmo, entre aspas, uma vez que a naturalização nada mais é do que o efeito de um amplo sistema de produção e reprodução de discursos sobre aquele fenômeno.

Evidentemente podemos encontrar vetores disruptivos no sentido inverso ao da estabilização, que estão também em operação e que possibilitam emergências de discursos inesperados sobre variadas situações. São esses discursos que podem pôr em movimento a estabilidade, num verdadeiro campo de disputa discursiva, e permitindo criar redes de contextualização.

Em nosso trabalho, estamos especialmente preocupados em identificar como duas dessas figuras de historicidade (o documental e a fabulação) podem operar em expressões televisivas de modo que os objetos tomados como focos dessa análise optam, em seu aspecto constitutivo, para uma ou outra dessas figuras. Desse modo, ao tomarmos contato com as edições do Ensaio percebemos uma tessitura que se apoia, predominantemente, no gesto documental do testemunho histórico, mas isso não inviabiliza que as edições invoquem a fabulação como um gesto secundário, sobretudo na valorização da vida dos convidados. Por outro lado, as edições do Jornal da MTV, sobretudo por sua articulação com o campo da valoração, característica aos processos de crítica cultural, fazem emergir em maior grau a relação com gesto fabulatório, na medida em que constroem espaços de representação para o crítico que se confundem com uma performance de encenação, ao mesmo tempo, a força do discurso informativo, também presente no programa, se torna constitutivo de um documento.

Nesse sentido, entendemos que essas figuras de historicidade não se contrapõem entre si, mas se articulam de forma complexa, promovendo o que estamos chamando aqui de redes de contextualização. Redes de contextualização seriam, então, articulações narrativas entre aspectos históricos, políticos, estéticos, econômicos e culturais que fornecem os enquadramentos predominantes para acontecimentos e/ou fenômenos sociais. Essas redes de contextualização podem se reconfigurar em função de transformações 
nos elementos que as compõem, promovendo, desse modo, leituras contrahegemônicase/ou alternativas dessesmesmosfenômenose/ouacontecimentos. Vejamos, portanto, como Ensaio e Jornal da MTV constroem suas redes de articulação de modo ora a reforçar, ora a tencionar convenções estabelecidas.

\section{As formas do Ensaio}

O Ensaio tal como já descrito em outros momentos (Leal \& Azevedo, 2011; Azevedo, 2013; 2016) é um programa que chama atenção crítica por ter se tornado um dos mais representativos formatos televisuais brasileiros direcionados ao registro de nossa música popular. Foi concebido a partir da curiosidade e experimentação do diretor Fernando Faro (Faro, 2007). No site da TV Cultura, encontramos atualmente a seguinte descrição:

No ar desde 1990, Ensaio traza cada programa um artista diferente que, além de cantar, fala do trabalho, da vida particular e relembra casos vividos. Apresentado por Fernando Faro, o acervo contém informações preciosas sobre os maiores músicos brasileiros (Ensaio, 2016).

Como essa descrição deixa de sinalizar suas origens, lembramos que o Ensaio passou pela Tupi nos anos 1960 e 1970 quando era chamado MPB Especial e nessa primeira fase teve participação de figuras como Novos Baianos, Elis Regina, Chico Buarque, Cartola, Nara Leão, Toquinho \& Vinícius, Lupicínio Rodrigues, Adoniran Barbosa dentre outros. Nos anos 1980 ele foi interrompido muito provavelmente com o fim da TV Tupi, mas volta a ser produzido pela TV Cultura no início dos anos 1990 tendo trazido nomes já consagrados como Baden Powell, Tom Zé, Gal Costa, Uakti, Tim Maia, Milton Nascimento e outros artistas ainda em processo de legitimação tal como vimos nos últimos 15 anos com a participação de figuras como Marcelo Jeneci, Mallu Magalhães, Charlie Brown Jr, Racionais MC's, Mariana Aydar, Tiago lorc, Los Hermanos, Péricles e diversos outros.

A primeira característica do Ensaio que nos chamou atenção era o modo como as entrevistas se desenrolavam em cada uma das edições: diferentemente do que estamos acostumados a ver em reportagens televisivas ou em talkshows, há um apagamento intencional daquele que faz perguntas e interage com os convidados. O próprio Fernando Faro, que faleceu em 2016, era a figura que guiava, fora do quadro televisivo, as conversas com os artistas fazendo perguntas que não escutamos. Aliado a essa característica, outro fator que sempre nos 
pareceu importante era a identidade visual assumida pelo programa que, além de trazer a fala dos músicos, preza pela performance musical dos mesmos. 0 Ensaio desde sua gênese faz uso de um cenário minimalista: um palco pouco iluminado sem adornos e sem auditório é ocupado apenas pelos corpos dos participantes e pela parafernália técnica usada para a captação audiovisual das performances (instrumentos, microfones, monitores sonoros, spots de luz e câmeras). Como consequência, a dimensão visual do programa coloca o corpo dos convidados como elemento central naquilo que se faz enquanto performance televisiva: a voz que conta histórias no Ensaio emana de um corpo majoritariamente registrado em super closes ganhando contornos de penumbra.

A partir de nossas preocupações específicas para essa reflexão, lidamos com o Ensaio a partir de algumas premissas: trata-se de um dispositivo narrativo (Azevedo, 2016) que, ao se apoiar nos relatos e performances dos convidados, arquitetou uma espécie de acervo monumental de parte de nossa música popular - com o tempo, inclusive, tornou-se uma espécie de palco legitimador para os artistas; o formato repete alguns procedimentos de edição e de organização audiovisual fazendo com que haja uma espécie de reconhecimento daqueles que o assistem; mesmo havendo esse caráter repetitivo, o programa parece abrir mão daquilo que seriam características gerais e usuais da linguagem televisiva dando aos convidados certa liberdade, algo raro no meio. No que se refere a essa última consideração, lembramos de momentos em que o imprevisto se torna um dos elementos mais importantes em suas edições: há diversos casos em que músicos se emocionam diante das câmeras; há muitos "erros" nas performances musicais; nos momentos de relato autobiográfico, os convidados - mesmo guiados por perguntas que não ouvimos - extrapolam, fazem rodeios, fogem do óbvio.

Nesse sentido, essa gramática de apagamento do próprio entrevistador nos faz refletir sobre o sentido fabulatório que emana da relação com o programa na medida em que os casos e opiniões partilhados aparecem como que "espontaneamente" dos convidados. Suas performances, tanto durante a execução das canções quanto nas conversas, indicam uma espécie de cotidianidade e, porque não dizer, uma continuidade entre vida e música.

\section{Vida e Música no Ensaio}

O Ensaio, em suas narrativas, coloca em relevo algo que é extremamente importante para a configuração de histórias que se contam sobre a música popular feita no Brasil. Em suas edições, tal como já mencionamos, há um apelo autobiográfico que parece conduzir as mais variadas participações naquele 
palco. Partindo disso, comentaremos um trecho exemplar do programa a fim de pensarmos como a articulação entre trabalho artístico e experiência de vida formam um amálgama muito potente no contexto de nossa MPB. Trata-se de uma edição que foi ao ar ainda nos anos 1970, contando com a intérprete Elis Regina como convidada. Nesse caso específico, o formato é apresentado como MPB Especial e, embora tal questão não seja o nosso foco, salientamos aqui que nessa época ele era registrado em preto e branco.

Elis Regina, em 1973, encontrava-se a todo vapor produzindo discos e fazendo shows. Já era conhecida em diversos cantos do país não apenas pelo trabalho fonográfico, mas também pela sua presença em programas televisivos. NoMPBEspecial, elafazuma apresentação econômica, algo dejazzística entoando canções de compositores como Tom Jobim, Gilberto Gil, Dolores Duran e Milton Nascimento. Ela fala de sua carreira, da infância, da família e das experiências como cantora. Em um trecho, por volta dos vinte e sete minutos de programa, Elis termina, com grande sorriso, a interpretação de Upa Neguinho (Edu Lobo/ Gianfrancesco Guarnieri). Seu rosto é registrado em um close frontal e logo após o fim da canção ela abaixa, levanta a cabeça e começa a contar um caso:

O Edu... foi uma pessoa que teve uma influência quase que definitiva na minha carreira, consequentemente na minha vida [...]. E, de repente, por essas coisas que acontecem, absolutamente independentes da vontade da gente, a gente... perdeu o contato que tinha, a gente quase não se vê mais. $E$, quando se vê, em geral não se fala. Mas... eu acho que o tempo é o melhor remédio para todo e qualquer problema que a gente tem. E eu tenho certeza que um dia eu e o Edu, a Wanda, as crianças que hoje em dia a gente tem, e o César... A gente vai sentar e conversar muito. E vai ficar realmente sabendo qual dos um mais um é realmente dois (Elis Regina: MPB Especial, 2004).

O tecer imagético que compõe esse trecho são os closes frontal e lateral do rosto da cantora entrecortados por imagens dos músicos que a acompanham. Nesse momento, a entonação e pontuação de sua voz imprimem seriedade, assim como desenham-se expressões austeras em sua face. Algo fica no ar, não sabemos o que aconteceu entre Elis Regina e Edu Lobo, aferimos que houve um desentendimento, algo mal resolvido. Mas temos uma certeza: a relação artística com um dos compositores de Upa Neguinho é algo que tem peso em sua vida pessoal: a cantora parece alterar suas emoções ao mirar uma das câmeras falando de seus desejos de reconciliação e mandando um recado aparentemente endereçado ao próprio músico. 
O registro tal como nos é apresentado parece querer nos colocar como cúmplices de uma desavença vivida por uma artista que, diante do aparato televisivo, parece estar entregue, tomada pela gravidade daquilo que pode ser causado pelo distanciamento de um amigo. Mais do que isso, o acontecimento construído ali figura parte da trajetória daquela que é considerada um dos maiores medalhões de nossa produção fonográfica. Aliás, a interpretação da canção em questão, inscreve outras possíveis relações históricas e que dizem respeito à mediação da canção popular no meio televisual. A partir dessa performance lembramos da premiação que Elis recebeu em 1965 ao defender a canção Arrastão (Edu Lobo/Vinícius de Moraes) no I Festival Nacional de MPB da TV Excelsior (Vilarino, 1999). De maneira semelhante, vem à memória o primeiro lugar em 1967 do III Festival de Música Popular Brasileira da Record: Arrastão (Edu Lobo/Capinam) defendida pelo próprio Edu ao lado de Marília Medalha e Quarteto Novo (Vilarino, 1999).Festivais como esses - e que tiveram suas finais televisionadas nos anos 1960 - podem ser tomados como um conjunto documental imprescindível para a legitimação daquilo que foi se estabilizando em torno da sigla MPB em termos estilísticos e performáticos nas décadas seguintes. A televisão, portanto, ajuda a operar quadros contextuais fundantes nos que se refere à música popular feita no Brasil.

Voltando ao MPB Especial de Elis, temos logo na sequência um relato da cantora sobre outro amigo; “[...] O Ciro é daquelas pessoas que... parece que... tentam, para mostrar para gente que... qual é o ideal... comportamento do ser humano. O Ciro foi realmente a melhor pessoa que eu conheci na minha vida [...]". A cantora fala pausadamente e, se antes projetava seu olhar para a câmera, nesse trecho ela abaixa a cabeça, esquiva-se daquele olhar de cumplicidade antes posto em cena. E, continua, agora levantando e abaixando o rosto, e com um tom de voz que sugere estar fragilizada: "[...] Eu tenho um carinho muito grande pelo Ciro e... inclusive o meu apelido quem me deu foi ele. Quer dizer, o apelido que eu tenho em casa [...]." (Elis Regina: MPB Especial, 2004). No fim dessa sequência em que presenciamos um relato mais emotivo, ela se põe a interpretar a canção Formosa (Baden Powell/Vinícius de Moraes), conhecida também na voz de Ciro Monteiro. Elis entoa a letra cantada com os olhos fechados e dá um tom intimista e passional à interpretação vocal, algo muito diferente da dicção mais debochada impressa por Ciro Monteiro no álbum Sr. Samba (CBS, 1961). Eis que, ao entrar na segunda parte da música, ela interrompe a performance, como se não desse conta de continuar e se esquiva novamente direcionando seu olhar para baixo.

Mais uma vez a cantora coloca a experiência vivida como algo íntimo de seu fazer musical: a canção trazida ajuda a compor, inclusive, a narrativa em 
torno de sua amizade com Ciro que havia falecido exatamente no ano de 1973 (Severiano, 2013). Mas os contornos que tal gesto ganha no programa nos faz atentar para outro aspecto importante: o resgate de uma velha canção nesse registro compreende um exercício de memória que se oferece a uma audiência ampla. Ao tomarmos contato com suas edições, estamos diante de capítulos de uma ampla historiografia apoiada no gesto documental. O Ensaio, assim, pode ser compreendido como um mediador que nos coloca em uma condição testemunhal. Antunes e Leal (2015) propõem o testemunho como uma figura de historicidade comum nos meios de comunicação: os autores trabalham a noção dando relevo a algumas dicções jornalísticas, mas nos parece cabível essa aproximação na medida em que o Ensaio se coloca não apenas como acervo, mas como uma espécie de mediador que esteve desde os anos 1960 acompanhando e registrando parte da história de música popular brasileira. Por fim, vale mencionar que há um gesto de preservação ligado ao nome do programa pois, ainda hoje ele é transmitido pela TV Cultura e outras emissoras públicas; além do mais, encontramos muitas das edições comercializadas no formato DVD.

\section{Formas do Jornal da MTV}

O Jornal da MTV foi uma proposta da extinta MTV Brasil de ressignificação de um dos gêneros mais populares da TV aberta, o telejornalismo, tendo o videoclipe como forma audiovisual de distinção e o campo da música popular massiva como tema da sua cobertura noticiosa. Não era um meio de performance musical, apresentava-se como um programa de notícias e crítica de música e, nessa perspectiva, parece-nos um objeto proveitoso para compreender aspectos constitutivos das performances e da memória televisiva e musical a partir de um outro viés: o entrelaçamento de convenções do campo do jornalismo e da cultura massiva. Movimento que se dá nessa interface entre regimes do "documento" e da "fabulação" como um padrão de construção narrativa. Diferentemente do Ensaio, a constituição de que poderíamos chamar de "realidade televisiva" não passa pelo «ato musical" em si, mas pelas disputas valorativas sobre ele (tem relevo aqui o lugar da crítica). O peso da conversação, convenção das performances televisivas no Jornal da MTV não se encontra no discurso biográfico e documental, mas na "entrevista informal" com os artistas da música pop e na ênfase da persona do apresentador do programa.

Apresentado, inicialmente, por Fábio Massari, o Jornal estreou em 2002 como um programa semanal de uma hora de duração, mas passou, ao longo dos seus cinco anos de exibição, por reformulações formais e discursivas que 
responderam por distintas e diferenciadas versões do programa ${ }^{3}$. Para os propósitos dessa reflexão, vamos tomar o ano de estreia como objeto de análise de modo a acessar como marcas da performance o que se diz sobre convenções relacionadas à emissora, ao consumo do rock, à indústria fonográfica, ao jornalismo, à crítica musical naquele tempo histórico.

As performances eram materializadas pelo corpo do apresentador e seus convidados, entrevistas no estúdio, formas de reportagem e videoclipe. Por conta do lugar que a crítica assume nesta versão do programa, é central a atuação do mediador. Diferentemente do Ensaio, a centralidade da voz do "crítico" marca toda a condução do programa. O apresentador Fábio Massari era personalidade conhecida no cenário fonográfico pelo seu perfil crítico e amplo conhecimento musical, fatos que Ihe renderam o apelido de "Reverendo". Tal postura é encarnada na sua atuação corporal. Explorava - diferentemente dos apresentadores de telejornal da época - expressões faciais, gestualidades, proximidades e distanciamentos da tela para se colocar no discurso enquanto sujeito que "conhece o campo musical" e que está autorizado a dizer "o que é bom" e "o que não é". A escolha do figurino de Massari, que usa camisas e suéteres geralmente em tons escuros, potencializa um clima casual para a cena. A aposta é reforçada pelo amplo cenário que oferece ao VJ maior mobilidade. Seus posicionamentos corporais ajudam a modalizar o que é dito verbalmente e configuram um meio de aproximação com o telespectador (Gutmann, 2011).

O enquadramento dado ao Jornal da MTV neste artigo também pressupõe algumas premissas: enquanto dispositivo narrativo, compreende construções de subjetividades que passam pelo reconhecimento do lugar do crítico, que se apoia em performances associadas ao apresentador de notícias e também ao consumidor de rock. O formato repete alguns procedimentos de edição e de organização do telejornal: presença da bancada e do tom azul do painel e logomarca como formas simbólicas autenticadoras, no texto verbal, os termos "notícia" e "reportagem" são regularmente proferidos, o nome do programa ("jornal"), os formatos de apresentação da notícia: nota coberta, reportagem, entrevista, escalada no início do programa (quando o apresentador indica

3 Em 2003, passa a ser veiculado quatro vezes por semana em um formato mais enxuto (meia hora) e investe na atuação de dois apresentadores, Edgard Piccoli e Rafa. Edgard Piccoli apresentava o Jornal da bancada, assumindo o papel de "âncora", já Rafa encenava o papel de "fã" e aparecia de dentro de um "quarto juvenil" (com pôsteres de bandas preferidas, uma cama, escrivaninha, mural de fotos). A segunda versão é replicada pelas demais edições. Em 2005, Sarah Oliveira assume a condução do programa ao lado de Rafa. Também foram apresentadores do Programa Carla Lamarca (2006), Léo Madeira (2006-2007) e Luisa Micheletti (2007). 
as manchetes do dia) etc. Apesar de não ser transmitido ao vivo, como os telejornais, recorria à forma do direto, com apresentação sem cortes, valorização do improviso e da espontaneidade das entrevistas como estratégias de autenticidade. Ao mesmo tempo, rompe com outras convenções formais dos gêneros informáticos ao valorizar o discurso pessoal e formas do videoclipe: sonorização das matérias, enquadramentos inusitados (planos oblíquos, closes cortados, por exemplo) saturação de cores, intervenções gráficas etc.

A proximidade reivindicada com a audiência se ancora no recorte temático (a música pop, em especial o rock) e na consequente partilha de gostos, hábitos e valores, o que significa reconhecer que os atores desse circuito comunicativo se colocam como sujeitos de uma mesma comunidade afetiva. O apresentador era autorizado a dizer explicitamente "eu", mas sua voz legitimada não é do músico e nem simplesmente a do "fã», é a do "crítico habilitado", daquele que tem autoridade para valorar ${ }^{4}$.

\section{O Crítico e o aficionado no Jornal da MTV}

A centralidade do Fábio Massari é marca do Jornal que reforça a convenção televisiva da figurativização do programa no corpo do apresentador. Ao se dirigir à audiência, o mediador também se apresenta como um tipo específico de apreciador que procura ser reconhecido como "conhecedor de música", "colecionador de obras musicais", fazendo-se confundir com suas próprias representações pessoais. Esta persona se relaciona à representação de um tipo de ouvinte que quer se distanciar da figura do "fã", cujo maior interesse estaria na vida de seus ídolos, e ser reconhecido como "aficionado", posição fundamental no programa para a compressão do lugar da audiência (espectador, consumidor de música). Haveria aqui uma distinção de comportamento (restaurado) no interior da música pop que marca o apelo de adesão ao programa. O lugar de fala dos espectadores do Jornal é o do tipo de ouvinte que ostentaria um maior interesse pela música em si, não pela "vida dos artistas".

O esforço de diferenciação aqui entre a figura do aficionado e do fã marca retoricamente o apelo de adesão do programa (Gutmann, 2011). Esses sentidos estariam num campo da sensibilidade onde a relação com os textos culturais "opera no domínio do afeto" (Grossberg, 1992). De acordo com Shuker (1999),

4 Maiores distinções desse processo de discussão entre crítico autorizado e ouvinte ordinário no campo da crítica midiática contemporânea foram elaboradas por Cardoso Filho \& Azevedo (2013), de modo que se identifica uma tendência de ampliação do universo da crítica contemporânea para atores sociais antes não "autorizados" - daí o grande interesse pelo discurso cotidiano de fãs e consumidores. 
esse tipo de apreciador seria qualificado pela procura por lançamentos raros e leituras de publicações especializadas e por um envolvimento secundário com os artistas e gêneros, e que procura discursivamente se distinguir daquele que acompanha os passos e vida dos artistas. O termo fã, contudo, quando revestido semanticamente ao fenômeno da "tietagem" e da relação de interesse pela imagem do ídolo ganha valor pejorativo entre os aficionados (Shuker, 1999) ${ }^{5}$. Assim, diferentemente das versões posteriores do Jornal da MTV, nas quais a figura do "fã" é materializada no corpo de um dos apresentadores, Rafael Losso, o Rafa, que entrou na MTV a partir de um concurso para VJ com telespectadores. O interlocutor convocado por essa primeira edição do Jornal é aquele identificado por Shuker (1999) como o ouvinte cujo interesse principal se centraliza na música em si, não nas celebridades pop.

Desse lugar de "aficionado", o acordo proposto com o público sobre a função dessa especialização discursiva é marcado pelo ajuizamento de valor das bandas, cantores e suas manifestações. E se, como sustenta Frith (1998), a produção de sentido da música pop passa pelos julgamentos ancorados em certas comunidades de sentido, aqui a mediação se vale da mesma estratégia. É dessa posição em relação ao simples tiete que Massarise posiciona como "jornalista", o sujeito legitimado a qualificar as obras e definir a experiência ideal para o seu público (Frith, 1998, p.67).

No dia 8 de novembro de 2002, por exemplo, ao entrevistar Jorge du Peixe, vocalista da banda Nação Zumbi, Massari recorre ao uso do pronome pessoal para enfatizar seu gosto pelo novo CD do grupo: "quero saber se vocês estão felizes com esse disco assim como eu e certamente muitos dos que já consumiram estão". O investimento nesse "eu individual" autorizado: "Eu conversei esta semana aqui na MTV com mais uma banda bacana que não é conhecida do grande público. Tô falando do som eletrônico do Bojo. Confira aí" (12.04.02). O delegado do discurso da emissora se faz confundir com as suas representações pessoais, esforçandose para imprimir uma marca individual no processo comunicativo, ainda que esta esteja sempre vinculada não só a um macro discurso "coletivo", o da MTV,

5 Reconhecemos os limites da tentativa de distinguir os supostos "fãs" dos supostos "aficionados", pois, na prática, é difícil separar os tipos de consumidores de música. A intenção de Shuker, portanto, é reconhecida aqui mais como uma estratégia retórica de posicionamento do que uma classificação de atuações empíricas. Assim, o "se colocar" como aficionado é entendido como uma estratégia de preservação do apreciador de música, que procura se diferenciar para evocar autoridade em relação a sua interação com as obras. Nessa perspectiva, essa distinção é adotada por esta pesquisa como uma estratégia discursiva apropriada pelas três versões do Jornal como forma retórica de se posicionar e posicionar os seus espectadores/ ouvintes ou como "fãs" ou como "aficionados". 
mas, e principalmente, aos valores da comunidade de conhecimento na qual se sustenta a mediação.

A cena criada, apesar de recorrer a um grau de cumplicidade, é marcada pelo tom pedagógico e por diferentes posições hierárquicas. A voz legitimada do crítico para relatar os assuntos é a do apresentador que, na tela, assume o papel de "Reverendo", daquele que sabe sobre o que fala e a partir de que local. Assim, ele é autorizado a emitir juízos de valor sobre as produções, construir as relações entre os temas, contextualizar bandas e cenas, apoiando-se num sistema gestual complexo do corpo para se colocar no discurso (expressões faciais, gestualidades, proximidades e distanciamentos da tela para se colocar no discurso). É forte o tom imperativo e instrutivo do apresentador: "Tem que ouvir", "Tem que ler" ou ainda "Tem que assistir" (Gutmann, 2011).

A crítica aqui tem como valor de diferenciação o sentido de autenticidade, critério central de avaliação sobre o mérito de artistas e suas obras. A tensão entre autêntico e cooptado responde pelo que é pautado no programa e pelo consequente julgamento das obras musicais. Artistas supostamente identificados com um estilo musical "comercial", cujas produções se adequam à ideia de "fórmula vendável", raramente são pautados. Quando noticiados, são apresentados a partirdeum enquadramentoque os identifiquecomo"cooptados".

O status conferido ao apresentador também se vale da questão do acesso às fontes (artistas, produtores musicais, VJs, jornalistas musicais). Sua credibilidade é sustentada pelo fato de se colocar, no texto, como aquele que "conhece" os artistas e produtores do meio musical, de modo que o clima de intimidade entre mediador e fonte se torna explícito. Os entrevistados vão ao programa não apenas para falar sobre o seu trabalho, mas, e principalmente, para se colocar como comentaristas dos fatos relatados. A intenção aqui é simular uma conversa entre membros de uma mesma comunidade de conhecimento apoiada no ritual valorativo. Entrevistado e entrevistador não olham para a câmara, dirigem-se um ao outro, o que provoca distanciamento da audiência. Nesse tipo de situação, o espectador parece ser posicionado como aquele que tem o "privilégio" de flagrar uma conversa que parece se desenrolar independentemente da câmera. A estratégia pode ser ilustrada pela edição do dia 8 de novembro de 2002 em que Massari recebeu três entrevistados: o guitarrista Yves Passarel e o vocalista Dinho Ouro Preto, do grupo Capital Inicial, e Jorge du Peixe, líder da banda Nação Zumbi.

Num dos momentos da "conversa", o apresentador diz: "Dinho, Du Peixe, conexão estabelecida. Chamei os dois justamente para convidá-los, e a rapaziada que assiste ao Jornal da MTV, para assistir em primeiríssima mão ao videoclipe da banda Audioslave". Massari oferece, em tom de empolgação, informações sobre 
a nova banda: "Chris Cornell nos vocais, ex Soundgarden, e os três remanescentes do RageAgains tthe Machine, banda muito citada aí como uma influência. $O$ resultado é explosivo e inacreditável, em primeiríssima mão, a gente confere aqui no Jornal da MTV. Daqui a pouco a gente bate um papo a respeito. Audioslave!". Após o trecho do clipe, os convidados compartilham o ritual valorativo:

\begin{abstract}
Massari - "Deu para arrepiar, não deu?". Dinho Ouro Preto - "Nossa cara o que é isso? Eu sempre achei o Chris Cornell, cara, era o vocalista que eu mais gostava de Seattle, o Soundgarden, né? Chocante a voz do cara". Jorge Du Peixe (em tom mais crítico) - "Rapaz, eu confesso que gosto muito mais de Zack de la Rocha ${ }^{6}$ ali velho". Massari - "É mesmo? Defendeu, defendeu". Dinho Ouro Preto - "Eu sou obrigado a comentar que o cara é muito bom também". Massari - "Foi certamente uma boa, uma fusão interessante, explosiva". Jorge Du Peixe- "Legal, bem produzido ali, sonzão potente pracaramba, mas tem que ouvir mais para comentar, né?" Massari - "É verdade, verdade. Eu entendo a conexão com Zack de la Rocha, Tom Morello também, grande guitarrista".
\end{abstract}

Nesse sentido, observamos como toda a situação da performance social aí exposta implica uma figuração narrativa amparada no flagrante do cotidiano dos participantes da cultura rocker. Ao mesmo tempo, as formulações pactuadas entre o Jornal da MTV e seu público quando pensadas pelo par "aficionados e críticos" remete ao campo das distribuições das fabulações, onde os afetados são colocados numa posição discursiva marcadamente mais frágil que aqueles que dominam um determinado código de conduta. Assim, entendemos que prevalece no Jornal da MTV uma figuração da historicidade mais próxima das fabulações, embora os motivos pelos quais predominam tais construções possam também ser problematizados.

\title{
Entre estabilidades e instabilidades (à guisa de conclusão)
}

A esse ponto nos parece importante destacar que tais sentidos sobre esses programas emergem a partir de um quadro referencial preocupado intimamente com a perpetuação da memória, o esquecimento e a construção dos cânones. Assim, se podemos identificar em Ensaio uma figuração testemunhal da démarche da música popular brasileira, em que artistas já consagrados revelam aspectos íntimos sobre seus processos produtivos quase

6 Zack de La Rocha era o vocalista da banda citada, o RageAgainst The Machine.

7 O guitarrista Tom Morello também era integrante do RageAgainst The Machine. 
que "espontaneamente", é porque o acionamento de dimensões da linguagem audiovisual, da cultura musical e das práticas sociais contribuem decisivamente para a configuração desses sentidos. Nessa perspectiva, um determinado acervo monumental vai se constituindo e um contexto específico se estabilizando.

Um processo semelhante ocorre quando observamos o Jornal da MTV e sua fabulação referente aos processos valorativos, seja na representação da fala autorizada do crítico ou na enunciação afetada do aficionado. Também aí observamos a tendência à estabilização, na medida em que a convenção instituída pela crítica cultural é notoriamente amparada nessa dicotomia. Por esse motivo, infere-se que a noção corrente de "contextualização" evoca a identificação desses quadros estabilizados, dito de outro modo, a identificação de aspectos hegemônicos que constituem os fenômenos.

Embora seja a noção corrente, entendemos que as redes de contextualização demonstram a potência de que aspectos disruptivos presentes na constituição desses fenômenos possam reconfigurar, inclusive, os quadros hegemônicos a partir dos quais são descritos, produzindo assim outras configurações de memória. No artigo em questão focamos especificamente esse potencial observando as performances sociais e demonstrando as tensões de coabitação das figuras de historicidade distintas nos programas televisivos: o documental e a fabulação. Como bem esboçado por André Brasil (2014) no seu ensaio A performance: entre o vivido e o imaginado, pode-se inferir que também aqui, nesses programas televisivos, a força performativa das imagens nos impõem não só representações, mas reinvenções mesmo da relação vida e música ou da atividade de crítica cultural.

\section{Referências}

AZEVEDO, Rafael José. O corpo audiovisual do cantor popular: Performances e gestos de Tom Zé no programa Ensaio. In: Revista Brasileira de Estudos da Canção, n.4. Natal: 2013. Disponível em: http://www.rbec.ect.ufrn.br/index.php/RBEC N4 A13. Acesso em: 18 jul. 2014.

. Tom Zé em Ensaio: Performances, canções, televisão. Belo Horizonte: PPGCOM - UFMG, 2016.

BRASIL, André. A performance: entre o vivido e o imaginado. In: PICADO, B; MENDONÇA, C; CARDOSO FILHO, J. (org.). Experiência Estética e Performance. Salvador: EDUFBA, 2014. 
CARDOSO FILHO, Jorge; AZEVEDO, Dilvan. Da sedução do argumento: dimensões (est) éticas da crítica midiática. In: DALMONTE, E. (org.). Teoria e Prática da Crítica Midiática. Salvador: EDUFBA, 2013.

CARLSON, Marvin. Performance: uma introdução crítica. Belo Horizonte: Editora da UFMG, 2009.

ENSAIO. Página do programa no site da TV Cultura, 2016. Disponível em: http:// tvcultura.com.br/programas/ensaio. Acesso em: 15 jan. 2017.

Elis Regina: MPB Especial - 1973. FARO, Fernando. 2004. 1 DVD (99 min.).

FARO, Fernando. Baixo: Homenagem ao maior produtor da MPB na televisão. São Paulo: Cultura - Fundação Padre Anchieta, 2007.

FRITH, Simon. Performing Rites: on the value of popular music. Cambridge Massachusset: Harvard University Press, 1998.

GALARD, Jean. A beleza dos gestos: uma estética das condutas. São Paulo: Edusp. 2008.

GROSSBERG, Lawrence. WeGottaGet Out ofthisPlace: Popular Conservatism and Post modern Culture. New York, London: Routledge, 1992.

GUTMANN, Juliana Freire. Estratégias de endereçamento da primeira versão do Jornal da MTV. In: GOMES, Itania Maria Mota (org.). Gêneros televisivos e modos de endereçamento no telejornalismo. Salvador: EDUFBA, 2011.

KOSELLECK, Reinhart. Futuro-passado: contribuição à semântica dos tempos históricos. Rio de Janeiro: Contraponto (PUC-Rio), 2006.

LEAL, Bruno Souza; ANTUNES, Elton. O testemunho midiático como figura de historicidade: implicações teórico-metodológicas. Chasqui - Revista Latinoamericana de Comunicación. v. 1, n. 129, ago./nov., 2015.

LEAL, Bruno Souza; AZEVEDO, Rafael José. O som do Ensaio. Revista Logos: Mediações Sonoras. ed. 35, v. 12, n. 2, 2011.

SAPHIRA, Bruno. Na vertigem do cinema documentário: mise-en-scène, performance e acaso como meios de convivência da ficcionalidade no documentário brasileiro contemporâneo. 2016. 188f. Tese. (Doutorado em Comunicação e Cultura Contemporâneas). Faculdade de Comunicação, UFBA. Salvador, 2016.

SCHECHNER, Richard. Performance studies: an introduccion. 2 ed. New York \& London: Routledge, 2006.

SEVERIANO, Jairo. Uma história da música popular brasileira: Das origens à modernidade. São Paulo: Editora 34, 2013. 
SHUKER, Roy. Vocabulário de Música Pop. Tradução: Carlos Szlak. São Paulo: Hedra, 1999.

VILARINO, Ramon Casas. A MPB em movimento: Música, festivais e censura. São Paulo: Olhos d'Água, 1999.

Recebido em: 20/3/2017

Aceito em: 31/3/2017

Endereço dos autores:

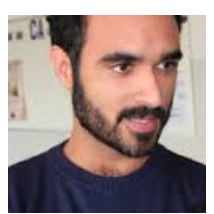

Jorge Cunha Cardoso Filho <cardosofilho.jorge@gmail.com>

Programa de Pós-Graduação em Comunicação e Cultura Contemporâneas

Universidade Federal da Bahia (UFBA)

Av. Barão de Geremoabo, s/nº - Campus de Ondina

40170-115 - Salvador (BA) - Brasil

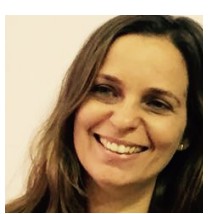

Juliana Freire Gutmann <jugutmann@gmail.com>

Programa de Pós-Graduação em Comunicação e Cultura Contemporâneas

Universidade Federal da Bahia (UFBA)

Av. Barão de Geremoabo, s/nº - Campus de Ondina

40170-115 - Salvador (BA) - Brasil

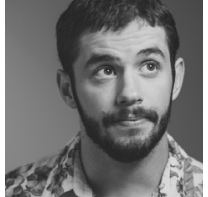

Rafael José Azevedo <rafaeljoseazevedo@gmail.com>

Programa de Pós-Graduação em Comunicação Social

Universidade Federal de Minas Gerais (UFMG)

Avenida Antônio Carlos, 6627 - Campus Pampulha - Sala 4234 - $4^{\circ}$ andar

31270-901 - Belo Horizonte (MG) - Brasil 